\title{
Empirical Method to Predict the Performance of Human Powered Mono Hull Boats
}

\author{
Pereowei Garrick Ombor ${ }^{1, a^{*}}$, Agbakwuru Jasper ${ }^{1, b}$, Okwu O. Modestus ${ }^{1, c}$ \\ ${ }^{1}$ Marine Engineering Department, Federal University of Petroleum Resources, Nigeria \\ aOmbor.pereowei@fupre.edu.ng \\ bagbakwuru.jasper@fupre.edu.ng \\ cmechanicalmodestus@yahoo.com
}

\begin{abstract}
Keywords: Human powered boat, performance characteristics, mono hull, propeller, deadweight coefficient, time to exhaustion. Speed, required power, cadence, RPM
\end{abstract}

\begin{abstract}
An empirical method to predict the performance of a human powered mono hull boat is presented in this paper. Results from the experiments were plotted in a graph format suitable for easy use to predict the performance of the boat under various operational conditions. Example cases were used to illustrate how the graphs are used. It was deduced from the graphs that it is possible to use human powered monohull boats to cover a distance as much as $81 \mathrm{~km}$ in less than 12 hours in sheltered waterways or rivers with minimal number of passing power boats. The results of the study also revealed that it is also possible for human powered boat user to travel a distance longer than $200 \mathrm{~km}$ when pedalling with input power less than 50watt. The study shows that there is high potential in the use of human powered mono hull boats for useful and sustainable transport purpose, especially in developing countries. The experimental method used in this study, proved that without conducting expensive resistance test in model basins, the performance of a human powered mono hull boat could be adequately predicted.
\end{abstract}

\subsection{Introduction}

There are lots of human powered boats (such as kayak, pedal boats, hydroski etc) in swimming pools and other shallow water bodies. These boats are generally used for recreational and competition purposes. They are very often designed based on elementary Archimedes principle. Apart from some of the boats used for competition whose data are often proprietary, the other human powered boats do not undergo careful scientific or technical performance evaluation owing to tight budget for one-off designs without model testing [1]. Consequently, there is a dearth of information and knowledge regarding the performance characteristics of human powered boats. This study seeks to add more information and knowledge about the performance characteristics of human powered monohull boats.

The research will help form a background for the investigation of the potential application of human powered monohull boats for useful transportation. It will provide insight into the hydrostatics and propulsive characteristics of human powered boats which largely define the possibilities that can be derived in the use of such boats.

There are various methods employed to predict the performance of ships [2,3,4]. Most of these methods involve estimating the ability of the ship's propulsion system to overcome the resistance of the ship at a given speed. In other words, the methods attempt to estimate the ships response to resistance and other prevailing factors when moving at a given speed under various operational conditions. The procedures generally entail using empirical (model testing) or analytical and graphical methods to understand the interaction existing among the hull, engine and propulsor. While these prediction techniques have been shown to reliably predict the performance of ships, they are less appropriate for human powered boats and need some form of modification to accommodate the peculiar characteristics of human power and propulsor used to provide propulsive thrust.

The input power and pedalling speed are quite low for extended period of boat usage (less than $200 \mathrm{~W}$ and $60 \mathrm{rpm}$ respectively) and the wake generated is very different from high speed vessels 
powered by other means. A little consideration on the power and RPM characteristics of the propulsive system of a human powered boat indicates that the boat is similar to ships powered by low speed engine with low MCR power. The characteristics of the boat can be likened to the least efficient operating point of a diesel engine layout diagram [4]. It can thus be deduced that for the efficient operation of a human powered boats, the principles used in diesel engine propulsion of ships will not exactly apply.

While it appears the human powered boat hull form can easily be derived from scaled down ships, they are usually not. Generally, the application of affine distortion method to scale down ships to a boat length (usually under $4 \mathrm{~m}$ ) appropriate for human powering ensures the boat possesses similar geometrical characteristics (identical main ratios and coefficients) with the basis ship [5]. However, such boats from scaled down ships have been observed to have small beams. Consequently, they suffer from transverse stability issues and are not applicable for useful and safe transportation purpose. The main dimensions and ratios must be modified to ensure stability requirements are satisfied. Inso facto, model results as well as the similarity laws applied to scaled down ships has questionable accuracy when applied to assess the performance characteristics of human powered boat [6].

Moreover, it is difficult to find models from methodical series that can be appropriately used as a human powered boat [7-14]. Most of the existing models have appropriate length (under 4m) but narrow beams and as such cannot contain a rider without capsizing. When most of these models are modified to satisfy speed, power and stability requirements of a human powered boat, the design parameters of the resulting boat often goes beyond one or more of the applicable hullform parameters limit (Length, Beam Length-Bream Ratio $(L / B)$, Length-Displacement Ratio $(\Delta / 0.01 L)^{3}$, Breadth-Draught Ratio, Block Coefficient $\left(C_{B}\right)$ and Prismatic Coefficient $\left.(C p)\right)$ and Froude number speed range of the methodical series [14]. It is therefore difficult to derive acceptable resistance and other performance characteristics of human powered boat from data derived from the existing methodical series.

Numerical and empirical methods exists to design and assess the performance of ships [2,16-19]. Most of the statistical methods are based on regression analysis of methodical series results, results from a wide range of tank towing experiments and actual ship data. Hence, they do have the inherent limited applicability as model tests results. The empirical methods are based on 'rule of thumb' and empirical equations which expresses the relationships existing between the many ship performance prediction variables derived from model tests. Most empirical techniques used for performance evaluation of small craft according to [19] has little or no experimental evidence. As such, the results from such analysis need to be validated against existing model experimental rsults. In the absence of such model experimental data, the parameters which influence the performance of the boat will be determined based on the designer's experience and judgement.

It becomes almost mandatory to conduct experimental test (not necessarily resistance test) on the prototypes of human powered boats to generate requisite data for the performance prediction of these boats. Conducting the traditional resistance experiments in a model basin or towing tank may not be necessary owing to the unique powering characteristics of a human powered marine boat.

This study reports series of tests conducted on a prototype pedal mono hull boat designed and constructed at the Marine Engineering Department Workshop in the Federal University of Petroleum Resources, Nigeria. The boat was designed within the extreme limits of the hullform parameters and speed range of the NPL high speed round bilge displacement hull series [7].

Performance data were experimentally generated for boat displacements of $110 \mathrm{~kg}, 154 \mathrm{~kg}$ and $198 \mathrm{~kg}$ which corresponds to deadweight coefficients of 0 (no additional load), 0.3 (additional $44 \mathrm{~kg}$ payload) and 0.4 (additional $88 \mathrm{~kg}$ payload). Deadweight coefficient is generally defined as the ratio of deadweight to the ship displacement $[5,21]$.

$$
\text { Deadweight Coefficient }=\frac{\text { Deadweight }}{\text { Ship Displacement }}=\frac{\text { Deadweight }}{\text { Lightship Displacement }+ \text { Deadweight }}
$$


The deadweight is the carryiong capacity of the boat consists of the payload, personal effects and/or passengers(s). For ships the deadweight consists of payload, ballast water, provisions, fuel, lubricants, water, persons and personal affects. The ship displacement is the sum of the lightship weight (weight of ship without additional load) and the deadweight. The lightship displacement of the boat herein is considered to be the weight of the empty boat and the propulsion machinery which consists of the pedal system and the rider who serves as the prime mover.

\subsection{Materials, Experimental Test Setup}

The experimental test should be conducted under suitable conditions using good quality test materials and equipment.

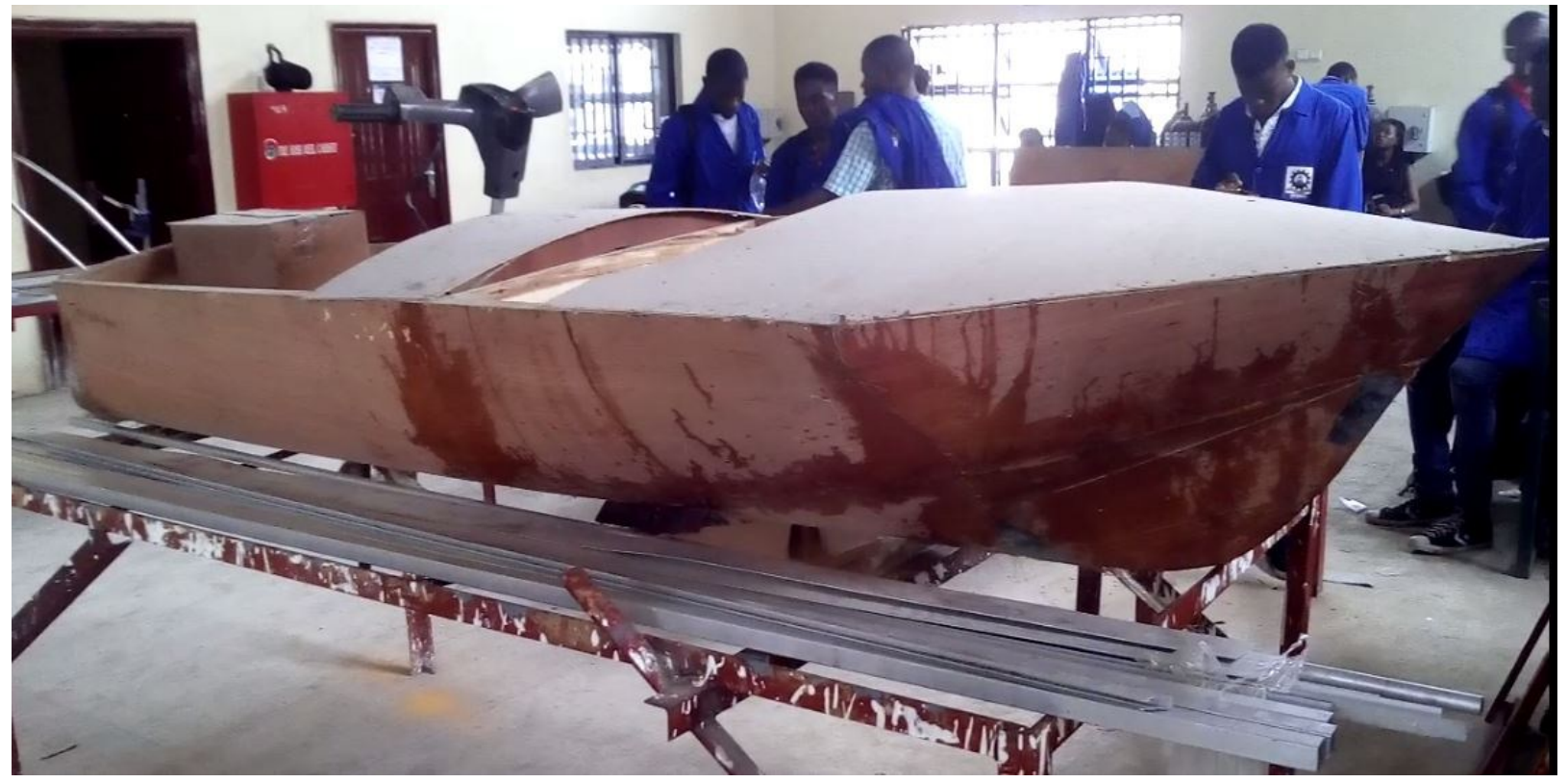

Fig. 1: Human powered boat

The boat used for this study is an NPL high speed round bilge displacement hull series shown in Fig.1. The boat particulars, materials, equipment and conditions for the experimental test are described in Table 1.

Table 1: Description of experimental requirements

\begin{tabular}{|l|l|}
\hline Experimental setup requirements & Value \\
\hline Boat particulars & \\
- Length Overall & $3.00 \mathrm{~m}$ \\
- Maximum Beam & $0.76 \mathrm{~m}$ \\
- Draught & $0.2 \mathrm{~m}$ \\
- Block Coefficient $\mathrm{C}_{\mathrm{B}}$ & 0.397 \\
- Prismatic Coefficient Cp & 0.693 \\
- Deadrise @ Transom & $12^{\circ}$ \\
- Half angle of entrance & $11^{\circ}$ \\
- Lightship displacement (including rider and pedal system) & $110 \mathrm{~kg}$ \\
- Propulsion Engine & Human powered pedal \\
- Gear ratio & $8: 1$ \\
- Propulsor type & 3 -bladed $0.38 \times 0.515 \mathrm{~m}$ \\
- Boat material & Plywood \\
\hline
\end{tabular}




\begin{tabular}{|c|c|}
\hline $\begin{array}{l}\text { Test participants (boat riders) } \\
\text { - } \text { No. of Participating riders } \\
\text { - } \text { Age (Years) } \\
\text { - Height }(\mathrm{m}) \\
\text { - Weight }(\mathrm{kg})\end{array}$ & $\begin{array}{l}2 \\
22 \pm 4 \\
1.7 \pm 0.2 \\
60 \pm 2\end{array}$ \\
\hline $\begin{array}{l}\text { Environmental conditions } \\
\text { - River course depth } \\
\text { - River condition } \\
\text { - Weather condition } \\
\text { - Suitable river reach for the experiment }\end{array}$ & $\begin{array}{l}6 \mathrm{~m} \text { minimum } \\
\text { Calm and free from debris } \\
\text { Windless and no rain } \\
\text { Sheltered and near shore }\end{array}$ \\
\hline 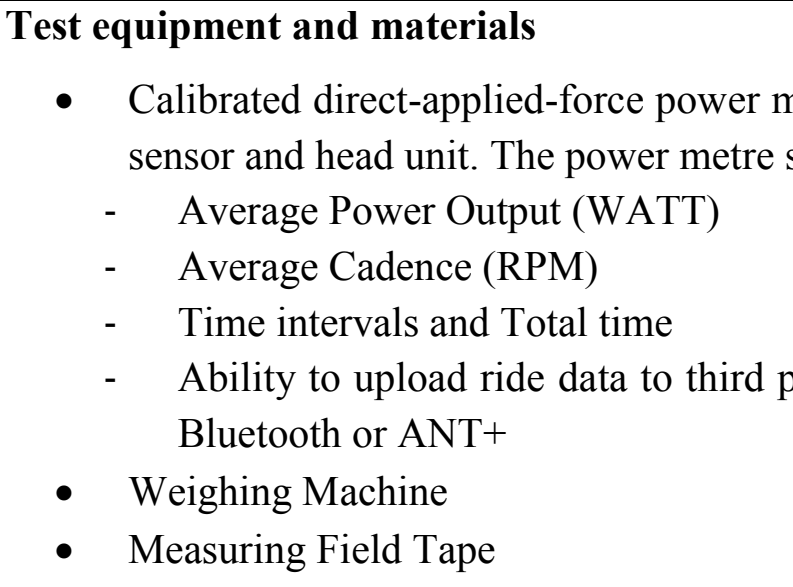 & $\begin{array}{l}\text { vireless connection between } \\
\text { puters or smartphone using }\end{array}$ \\
\hline Preliminary data gathering & \\
\hline $\begin{array}{l}\text { Prior to conducting the experiments, the follow } \\
\text { - Location, Date and Time } \\
\text { - Particulars of Participants } \\
\text { - Boat particulars and conditions such as } \\
\text { Depth. } \\
\text { - Fore and Aft Draught for each loading c } \\
\text { - Propulsion type and configuration }\end{array}$ & $\begin{array}{l}\text { e measured and recorded: } \\
\text { Length, Beam and Draught, }\end{array}$ \\
\hline
\end{tabular}

\subsection{Experimental Method and Procedures}

For each of the following deadweight coefficients $0,0.3$ and 0.4 , each rider is required to maintain the following average cadence (number of pedal revolutions in one minute) 10, 20, 30, 40, 50 and $60 \mathrm{rpm}$ which corresponds to 80,160, 240, 320, 400 and 480 propeller RPM for gear ratio 8:1. A total of 18 experimental ride sessions were carried out in this study by each rider.

To generate the relevant data for the performance assessment of the boat, each experimental ride session was divided into three (3) laps namely;

- First lap: Warm-up lap

- Second lap: Propulsion pitch determination lap

- Third lap: Time to exhaustion lap 
Each participating rider is required to go through these three laps for each experimental ride session. For each session, one rider moves the boat to one end of the river course while the other rider returns the boat to the side the first driver started from. Consequently, for each cadence experimented for a given deadweight coefficient, two sets of readings are recorded. It should be noted that the time to exhaustion and distance travelled for a given cadence most times varied from one rider to another. The power, cadence time to exhaustion and distance used for the performance assessment are respectively the average of the sum of the average power, total cadence and time to exhaustion values recorded for both participants in the second and last laps of the experiment.

\subsection{Warm-up Lap}

In this lap, the rider is allowed to pedal the boat until the specified average cadence for the experiment is attained. After attaining the specified Average cadence, the lap ends with the beginning of the second lap (pitch determination). Specified average cadence for this study are 10, 20, 30, 40, 50 and 60rpm

\subsection{Propulsion Pitch Determination Lap}

The distance covered by the boat when the rider pedals one revolution is regarded as the propulsion pitch of the boat. To determine the average propulsion pitch of the boat, the rider is required to maintain the specified cadence for one minute. The ride time, average watt power, average cadence and total number of revolution data are recorded by the power meter over the one minute time interval. The total distance covered is measured with the field tape. This lap of the experiment is completed at the end of the one minute period.

The propulsion pitch of the propeller for the boat is given as:

$$
\begin{aligned}
& \text { Propulsion Pitch }=\frac{\text { Total distance covered in one minute }}{\text { Total propeller RPM measured during the one minute }} \\
& \text { Propulsion Pitch }=\frac{\text { Total distance covered in one minute }}{\text { Gear Ratio } \times \text { Total cadence measured in the one minute }}
\end{aligned}
$$

The starting position of the boat during this lap of the experiment was taken at the transom position of the boat at the end of the warm up lap. The starting position was marked with a peg ashore by a research assistant. The end point of this length is at the boat transom position at the end of the one minute. This point was also marked with a peg ashore. The distance between the start and end positions of this lap of the experiment after 1 minute ride was measured with the field tape with the help of research assistants.

The actual propulsion pitch of the propeller for a given pedal cadence of the boat is herein considered as the average value of the propulsion pitch from both participants involved in the experimental execises for that pedal cadence.

$$
\text { Average Propulsion Pitch }=\frac{\sum_{i}^{K}(\text { Propulsion Pitch })_{i}}{K}
$$

Where $i$ is a given propulsion pitch and $\mathrm{k}$ is the total number of propulsion pitches

\subsection{Time to Exhaustion Lap}

This is the final stage of the experiment where each rider is required to maintain the specified cadence until exhaustion. The time to exhaustion is the time when the rider observed that the cadence under consideration can no longer be sustained after making three consecutive efforts.

During this lap, the head unit of the power meter was made to record and store raw data such as ride time, average power $\mathrm{P} i$ (watt) and cadence (RPM)

The distance (S) covered by a rider $i$ during the second and third laps for a given pedal cadence can be determined thus: 


$$
S_{i}=\text { Total propeller revolutions during phases } 2 \text { and } 3 \times \text { Propulsion pitch }
$$

The average distance $\mathrm{S}_{\mathrm{Av}}$ covered by the two riders for a given pedal cadence is given as:

$$
S_{A V}=\frac{\sum_{i}^{K} S_{i}}{K}
$$

Where,

$i$ represent a rider used for an experimental ride session

$\mathrm{k}$ represents the total number of riders.

The speed (V) at which the boat is moved by a rider $i$ during the second and third laps for a given cadence can be determined thus:

$$
V_{i}=\frac{s_{i}}{\text { Time to exhaustion starting from the second lap }}
$$

The average speed $\mathrm{V}_{\mathrm{Av}}$ the boat moves for the two riders for a given cadence is given as:

$$
V_{A V}=\frac{\sum_{i}^{K} V_{i}}{K}
$$

The average power expended for a given cadence by the two riders for the second and third laps is given as:

$$
P_{A V}=\frac{\sum_{i}^{K} P_{i}}{K}
$$

Where,

$\mathrm{P}_{i}$ is the average power recorded for rider $i$

\subsection{Experimental Results}

All the data recorded in the head unit of the power meter was transferred via a USB cable to a personal computer for analysis.

At present there is no standard method of presenting ship model experimental data [6]. The most useful method for data presentation is dependent on the purpose for which the data will be used. The data gathered during the experiment is presented in graphical form as shown in Figures 2 to 5 to allow the user easily understand the relationship existing among the various pertinent performance parameters.

In Fig.2, comparison was made for input power at various propeller RPM for various deadweight coefficients. While in Figures 3 to 5, the Time to exhaustion, Propeller RPM speed, Required power parameters were plotted against the boat speed. 


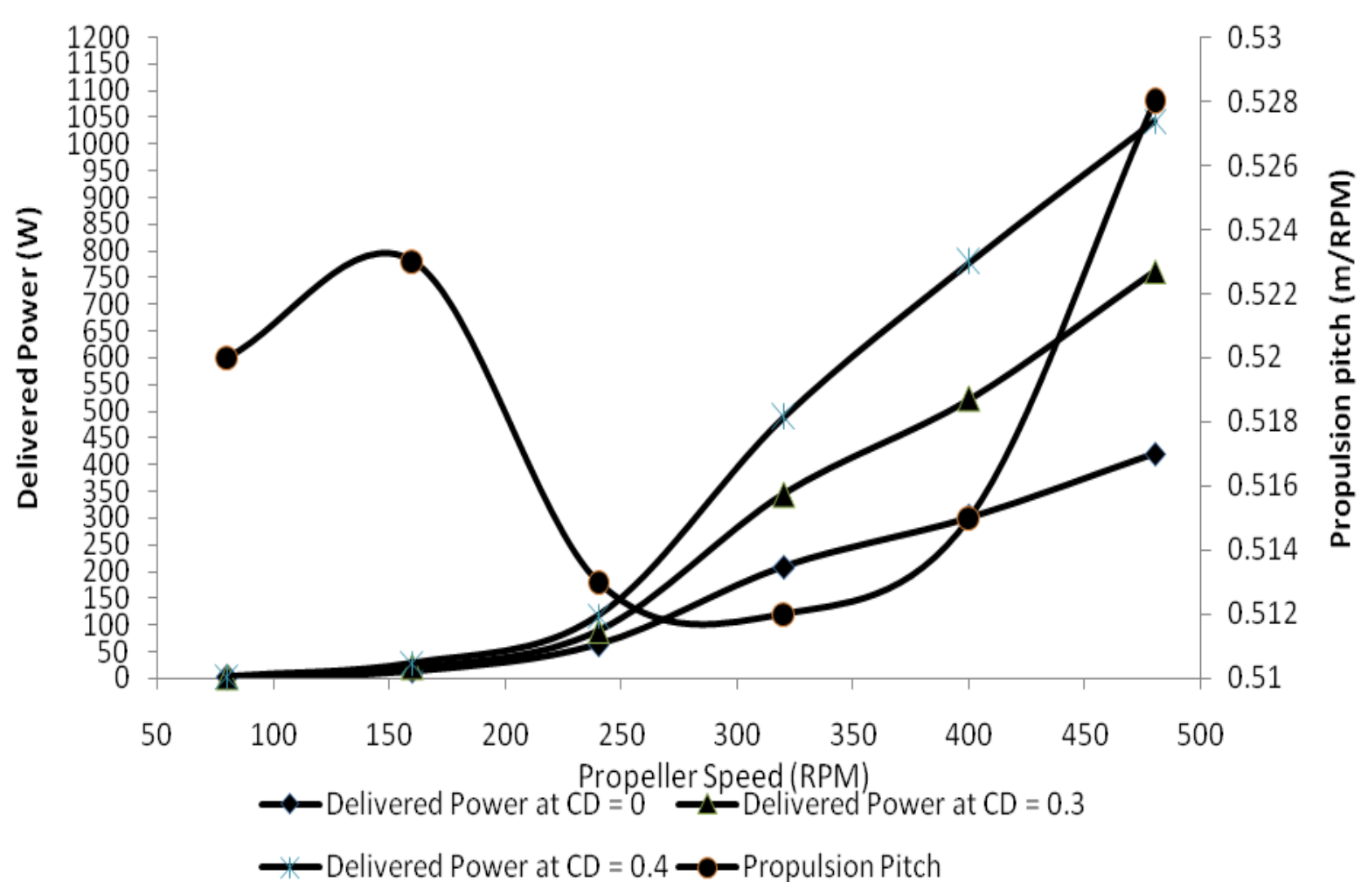

Fig. 2: Required Power (W) and Propulsion Pitch for various Propeller Rotational Speed

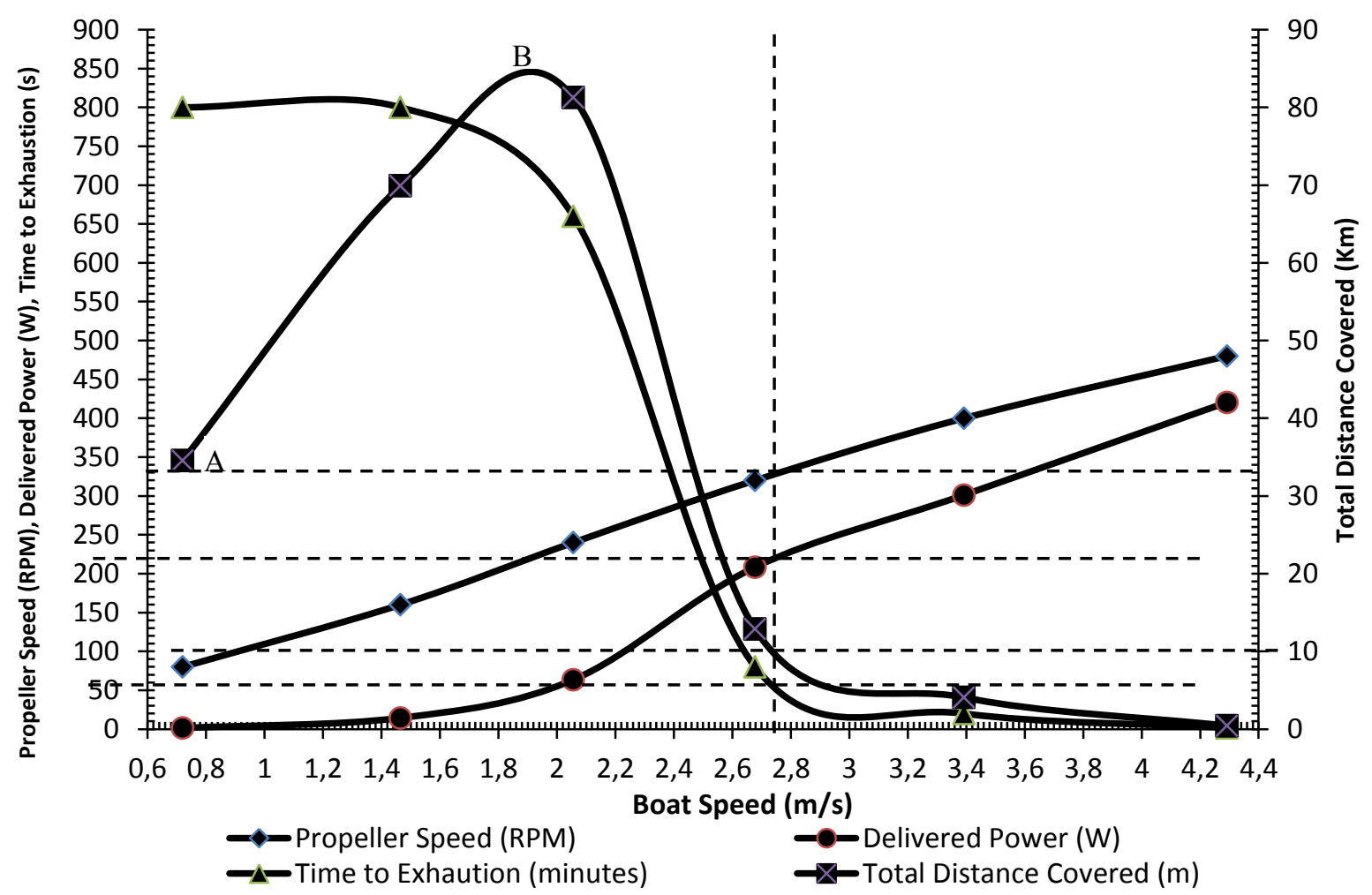

Fig. 3: Performance characteristics for Deadweight Coefficient $C D=0$ 


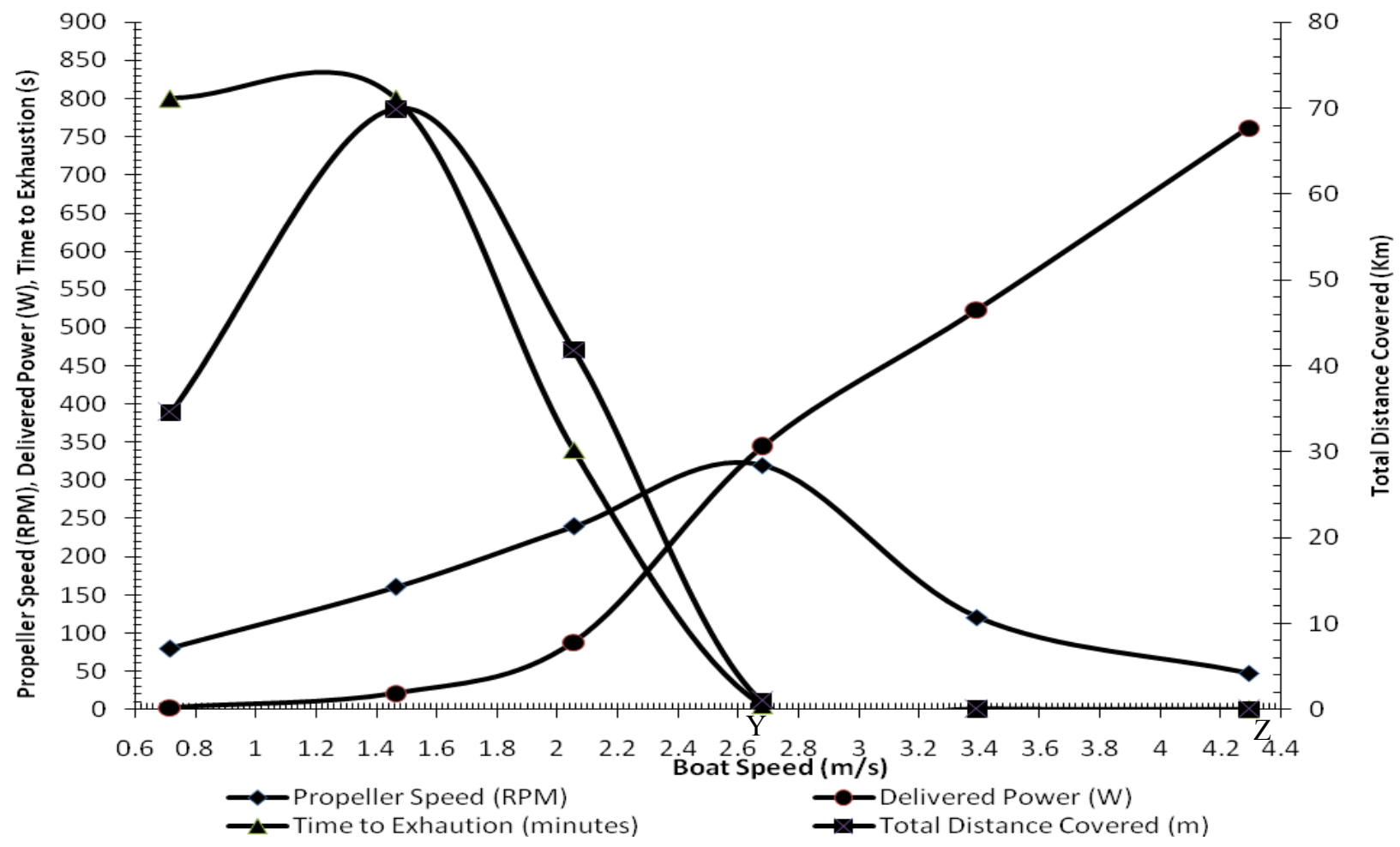

Fig.4: Boat Performance Curves for Deadweight Coefficient $C D=0.3$

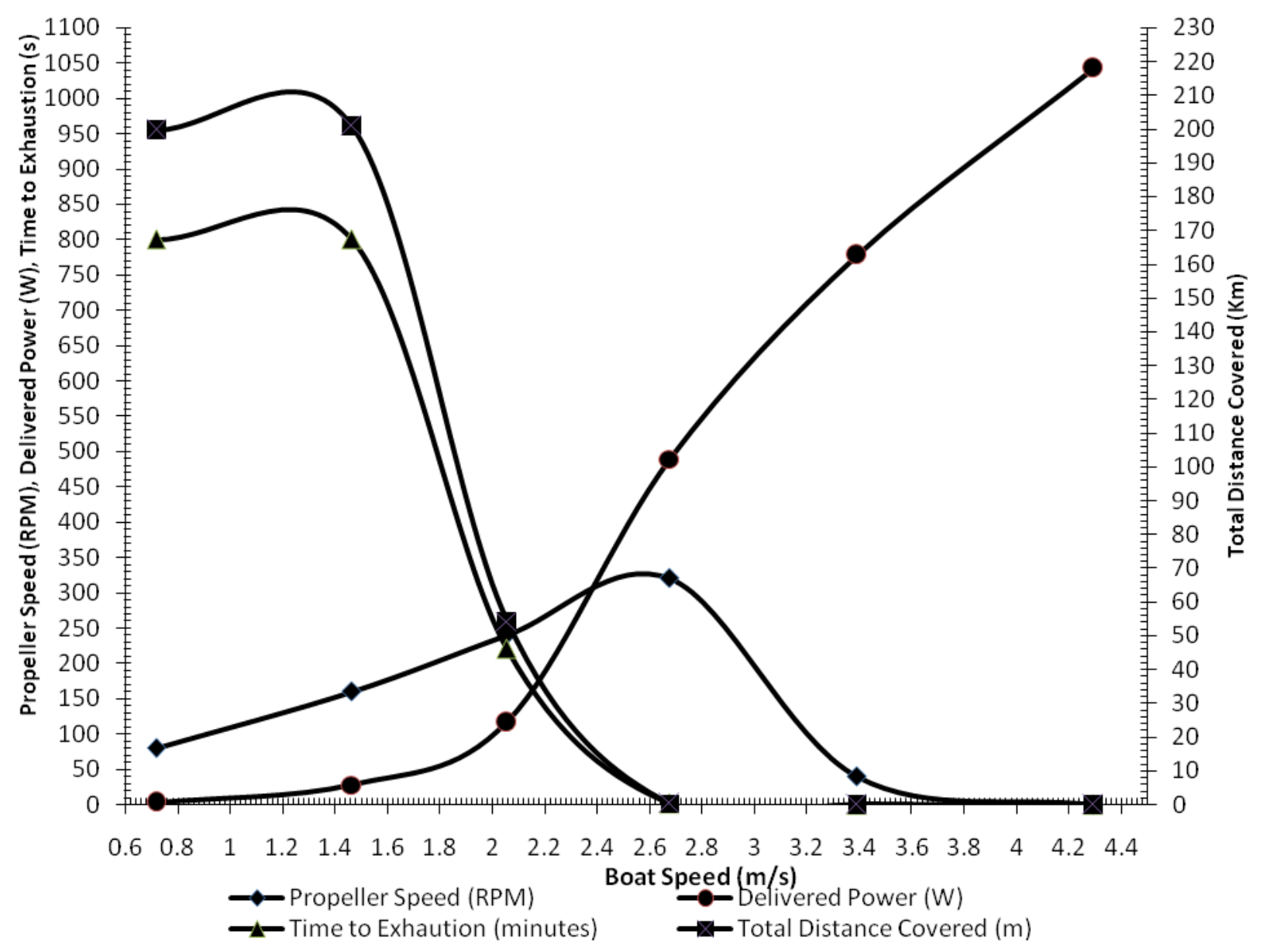

Fig. 5: Boat Performance Curves for Deadweight Coefficient $C D=0.4$ 


\subsection{Results and Discussion}

The data generated from this study exclusively apply to geometrically similar human powered boat with identical propulsion system as that used for the boat in this study. In Fig.2, The propulsion pitch in the course of the experiment was found to be between 0.5 to 0.52 for the range of cadence (or propeller RPM) considered in this study. The variations may be as a result of minor errors made in the distances measured at the decided the start and stop location of second lap of the experiments. Where the exact start and stop points are not precisely located, the distances measured will have some errors. However, the propulsion pitch variation is quite minor and acceptable. It is also observed in Fig. 2 that as the deadweight coefficient is increased, the power requirement also rises for a given pedalling cadence.

From Figures 2 to 5, it can be observed that as the CD increases, the power required to move the boat at a given cadence (propeller rpm) increases, the rider becomes exhausted at shorter travelling times. As such, the possible distance that can be covered for a particular propeller RPM decreases as the $\mathrm{CD}$ increases.

The reason for this shorter distance can be explained when we consider the boat at different loaded conditions (say $\mathrm{CD}=0$ and $\mathrm{CD}=0.4$ ). When the $\mathrm{CD}=0.4$, the rider must apply greater effort on the pedal to maintain the same propeller RPM speed as when the boat's CD $=0$. In doing so, the driver gets exhausted sooner, thereby covering lesser distance compared to a boat with $\mathrm{CD}=0$, where the riding time for the rider is extended further. Therefore, it can be concluded that the lesser the CD for a given propeller RPM speed, the more distance the boat can cover.

One notable feature in the distance covered and time to exhaustion curves is the flat YZ limb shown in Fig. 4 as well as in Fig.5 (charts for higher CD). These limbs indicate an operational mode where the power input to the pedal to satisfy the required experimental cadence to move the boat at a particular speed is excessive for the riders. During this operational mode, as the power requirement increases, the cadence (propeller RPM) rapidly approaches zero as shown in the RPM curves in both figures 4 and 5. The riders' cadence recorded was found to be a fraction of the required experimental cadence for that experimental session before riders were exhausted, the riders could not complete 50 pedal (400 propeller) revolutions in one minute. Inspite of the effort put in by the riders, the boat moved a very short distance, less than $50 \mathrm{~m}$ before the riders got exhausted in less than one minute

For practical and useful transport purpose of boats geometrical similar to the boat under consideration, the above charts can aid the user to select the appropriate set of boat speed, pedalling cadence and powering to reach a specified distance within a specified time. For instance, consider a user of the human powered monohull boat carrying $5 \mathrm{~kg}$ personal effects, who wants to travel from community $A$ to another community $B$ which is $10 \mathrm{~km}$ apart. If the weight of the user is $55 \mathrm{~kg}$ and the weight of the empty boat is $50 \mathrm{~kg}$, then the resulting boat displacement is $110 \mathrm{~kg}$ which correspond to $C D=0$ in this study. Therefore Fig. 3 is the most applicable figure to use for the performance analysis. Where the boat displacement does not fit any of the performance graphs, interpolation method involving two nearest graphs may be applied.

The user is required to draw a horizontal line from the $10 \mathrm{~km}$ point on the distance axis to cut across the other curves. At the point where the line touches the distance curve, a vertical line is erected across all the performance curves. We can deduce the time the user will get exhausted by locating the point where the vertical line touches the time to exhaustion curve. This time is found to be 55 minutes and the corresponding boat speed is $2.75 \mathrm{~m} / \mathrm{s}$. Similarly, by locating where the vertical line touches both the power and propeller speed curves, the power required to the propeller and propeller RPM speed were determined to be 230watt and 330RPM (pedal cadence of 41RPM) respectively. A brief consideration of the power and RPM requirements revealed that a considerable amount of effort is needed by the user. A trained athlete can easily meat these requirements.

The user can also use the chart to determine the performance requirements to cover the same distance under 45 minutes. To do this analysis using the chart, the user must first determine the propeller revolutions per minute by using the following equation derived from eq. 2 as follows 


$$
\text { Total propeller RPM }=\frac{\text { Total distance covered in one minute }}{\text { Average Propulsion Pitch }}
$$

$$
\text { Total propeller revolution }=\frac{10000}{0.51}=19608 \text { revolutions }
$$

Propeller Revolution per minute $=\frac{19608}{45 \text { minutes }}=436 R P M$, which corresponds to a pedal cadence of 55RPM.

Having determined the required propeller speed, an horizontal line is drawn from the 436RPM point on the propeller RPM axis to touch the propeller RPM curve. At the point where the horizontal line touches the propeller RPM curve, a vertical line is erected across all the performance curves. The points where the vertical line touches the boat speed horizontal and the power curve indicates the required boat speed and required power respectively. From Fig.3, the required speed the boat should travel is $3.8 \mathrm{~m} / \mathrm{s}$ (7.4knots) and power the rider must deliver to the propeller is about 350 watts. A brief consideration of the power requirement shows that the rider will have a difficult time travelling at this power input of 350 watts which is greater than the optimal power input ( $<200$ watts) required by an average athlete for long distance pedalling.

It should be noted that, the performance graphs in this study do not consider situations where the propeller RPM is greater than 480. It should also be noted that each experimental ride session was conducted for a maximum of 12 hours ( 800 minutes). Hence, the falling limb portion $A B$ in the distance curve of Fig. 3 does not represent the actual possible distance that can be covered. For CD $=0$, it was observed during the experiment that the participants were not physically exhausted after pedalling at 10RPM and 20RPM pedal cadence during the full session of 12 hours, however, the experimental exercises were truncated owing to time limit and other considerations. The $A B$ portion would have pointed upward if the experiment was continued over night.

The charts show that it is possible to use human powered monohull boats to cover a distance as much as $81 \mathrm{~km}$ in less than 12 hours in sheltered waterways or rivers with minimal number of passing power boats. It also revealed that it is possible for a human powered boat user to travel a distance longer than $200 \mathrm{~km}$ when pedalling with input power less than 50 watt. However, to cover such distance, the rider will travel at speed lesser than $3 \mathrm{knots}$ and at much longer time.

This study shows the high potential in the used human powered boats for useful and sustainable transport purpose, especially in developing countries.

\subsection{Conclusion}

The results of the study give a clear indication of the useful potentials and limits of human powered mono-hull boats. The results show that it is possible to use human powered monohull boat to cover a distance as much as $81 \mathrm{~km}$ in less than 12 hours in sheltered waterways or rivers with minimal number of passing power boats. It is also possible for human powered boat user to travel a distance longer than $200 \mathrm{~km}$ when pedalling with an input power less than 50watt. It was observed that as the the boat is loaded to increase the value of $\mathrm{CD}$, the power required to move the boat at a given propeller rpm speed increases and the rider becomes exhausted at shorter travelling times. It was shown that before a rider gets exhausted, the total distance covered when the boat is loaded to $\mathrm{CD}=$ 0.4 is shorter than when the boat is unloaded (i.e. when $\mathrm{CD}=0$ ).

The study revealed that the performance of a human powered mono hull boat with geometrically similar hull form and similar propulsion system as the boat used in this study, can be adequately predicted empirically at minimal cost without conducting a resistance test in a towing tank. However, the time and energy spent on gathering data in this study was much compared with other experimental performance assessment of marine vessels. Researchers can make use of the results of this study to validate the results of newly developed analytical or theoretical models for predicting the performance of human powered mono hull boats. 


\section{References}

[1]. D. M. MacPherson, The Ten Commandments of Reliable Speed Prediction, Small Craft Marine Engineering Resistance and Propulsion Symposium, University of Michigan, (1996).

[2] D. Savitsky, Hydrodynamic design of planing hulls, Marine Technology, 1(1) (1964) 71-95.

[3] D.J. Taunton, D.A. Hudson, R.A. Shenoi, Characteristics of a series of high speed hard chine planing hulls - Part 1: Performance in calm water. RINA-IJSC (1996)

[4] Basic Principles of Ship Propulsion, DIESELFACTS 1-2012, Man Diesel and Turbo. www.mandieselturbo.com

[5] H. Schneekluth and V. Bertram, Ship Design for Efficiency and Economy. Second edition, Butterworth-Heinemann, Woburn, MA 01801-2041, 1998.

[6] V.L. Edward, Principles of Naval Architecture, Volume II, Resistance, Propulsion and Vibration, Second revision, The Society of Naval Architects and Marine Engineers, New Jersey, 1988.

[7] D. Bailey, The NPL high speed round bilge displacement hull series, the Royal Institution of Naval Architects, 1976.

[8] D.W. Taylor, The speed and power of ships, Second revision, US Maritime Commission, 1943.

[9] F.H. Todd. Series 60 methodical experiments with models of single-screw merchant ships, DTRC, TMB Report 1712 (1963).

[10] J.N. Nordstrom, Some systematic test with models of cargo vessesl with block coefficients 0.575 , SSPA 16 (1951).

[11] J.N. Nordstrom some systematic test with models of small vessels, SSPA 19 (1951).

[12] A.O. Warholm, Systematic test with models of coasters SSPA 24 (1953)

[13] U. Kiel and P. Schenzle, Modellversuche mit Extreme Breiten SchiffsformenWilderstandsversuche mit Extreme Breiten Schiffsformen $(\mathrm{Cp}=0.77)$, institut für schiffbau der Universität Hamburg, Bericht 333 (1975).

[14] P. van Oossanen, Resistance prediction of small high speed displacement vessels: state of the art, Symposium on 'The impact of 200mile economic zone' organised by the Royal Institution of naval Architect and the Institute of Marine Engineers, Sydney, Australia (1979).

[15] D.J. Doust, and T.P. O'Brien, Resistance and Powering of Trawlers. Transactions of the North East Coast Institute of Engineers and Shipbuilders 75 (1959).

[16] F.H. Todd Resistance and Propulsion. Principles of Naval Architecture. Chaptervrn, The Society of Naval Architects and Marine Engineers, NewYork, 2nd Edition 1967.

[17] C.C. Schneiders, Should Ship Performance be Predicted by Calculation, The Naval Architect. (1990).

[18] J.R. Kizer, Development of parametric sizing and synthesis tool for the design of planing hull watercraft, Aerospace Systems Design Lab, School of Aerospace Engineering, Georgia Institute of Technology (2011).

[19] F.C. Michelsen, J. L. Moss, J. Koelbel, D. Savitsky, H. Appolonio Small Craft Engineering: Resistance, Propulsion and Seakeeping, Department of Naval Architecture and Marine Engineering, The University of Mitchigan, 20 (1971).

[20] P. Young and J. Kemp, Ship stability notes and examples, Second edition, ButterworthHeinemann, Woburn, MA 01801-2041, 1998 